\title{
Addressing the issue of underrepresentation of women in Chemistry
}

\author{
Asalat Kamal, Michael Kang and Benjamin \\ Mong
}

\section{Abstract}

We conducted a study in two different high schools in Mississauga to see if there was a correlation between gender and interest to study Chemistry after high school. A vast number of adolescent females reported no interest in studying Chemistry (65\%) compared to adolescent males $(26 \%)$. Our research suggests that disproportionally of women to men in Chemistry may originate as early as

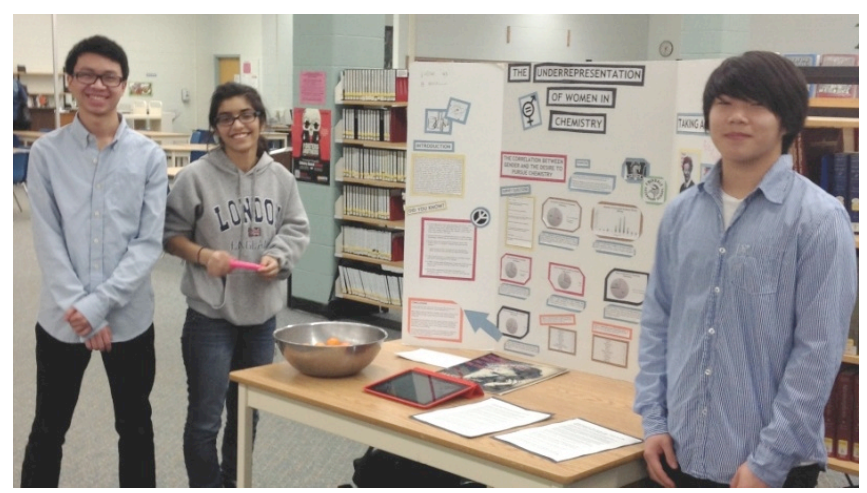

high school. We recommend that high school Science/ Chemistry curriculum must be more inclusive to help young girls develop an interest in Chemistry, and Science in general. Teachers must combat stereotypes in the classrooms and introduce young women to more female role models in Science/Chemistry to empower them to pursue Chemistry in post-secondary years.

Benjamin Mong, Asalat Kamal and Michael Kang present their research-informed action project about the underrepresentation of women in chemistry during the 2012-2013 STSE fair at Erindale Secondary School. 


\section{Introduction}

At the 2010 TedGlobal conference, Pulitzer Prize winner Sheryl WuDunn stated that gender inequality is becoming the leading injustice of the 21 st century. Similarly, in 2007, when presenting to a segregated audience in Saudi Arabia, business mogul Bill Gates was asked if it was realistic for Saudi Arabia to aim to be one of the leading country in the field of technology by 2010 . Gates' response was simple: "Well, if you're not fully utilizing half the talent in the country, you're not going to get too close to the top..." (Associated Press, 2007).

WuDunn and Gates are just a fraction of the influential activists that are forcing the international community to recognize the underrepresentation of women in Science, Technology, Engineering and Mathematics (STEM) fields and the inequalities they face compared to men. Even though women fill half of the job positions available in the U.S, and, consequentially, constitute half of the U.S. economy, they fill 24 percent of STEM positions. In addition, women with a STEM undergraduate degree are less likely to pursue a career in STEM fields. These women are more likely to acquire positions in education and healthcare ("Women in STEM: A Gender Gap to Innovation”, n.d.).

\section{Focus of the Study}

We conducted a study to investigate whether a correlation existed between an individual's gender and an interest to study Chemistry at a post-secondary level in

\section{Research Method}

We asked 240 senior students (120 male and 120 female) from two high schools in Mississauga, Ontario, to complete a short survey consisting of six questions. These individuals had to have completed, or were in the process of completing, one senior Chemistry course. We followed this criterion when selecting individuals to participate in our study because the questions we asked required experience in a Chemistry classroom. We asked the following questions:
No definite answer can be given to explain the underrepresentation of women in STEM fields. Social scientists have brainstormed some possible factors such as a lack of role models for females in the STEM fields, gender stereotyping in the media, and family obligations that women are struggling to fulfill because of the nonflexible schedule of STEM positions ("STEM Fields And The Gender Gap: Where Are The Women?”, 2012).

A lack of women entering STEM fields is a hindrance to our nation' economy as well. Women in STEM positions earn 33\% more than women in non-STEM positions ("Women in STEM: A Gender Gap to Innovation", n.d.). With little women entering STEM fields, a nation's economy is not at its highest potential. Powerful nations like Canada have a responsibility to send a positive message to the international community about the incorporation of women in STEM fields. Girls in high school need to be empowered by their teachers and their parents. Teachers play a central role in empowering young women to pursue STEM fields. Women have great potential in these fields. Their success can lead to our nation's success and to a more equitable and inclusive society for all.

two high schools in Mississauga. In addition, we also asked how well Chemistry is taught in high school and if our peers think that gender bias exists in Chemistry.
- What is your gender? Male or Female

- Are you interested in studying Chemistry at a postsecondary level? (Yes or No)

- Why or why not? Please explain briefly.

- One a scale of 1 to 10 (with 10 being the highest quality), how well is Chemistry taught in high school?

- What can be improved? Make one suggestion.

- Do you think that there exists a gender bias in Chemistry? Circle one. (Yes or No) 


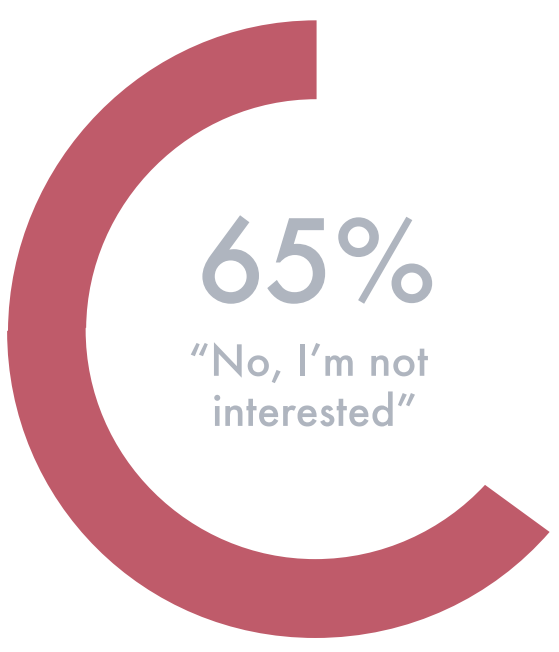

Figure 1: Proportion of girls who were interested /not interested in studying Chemistry after high school.

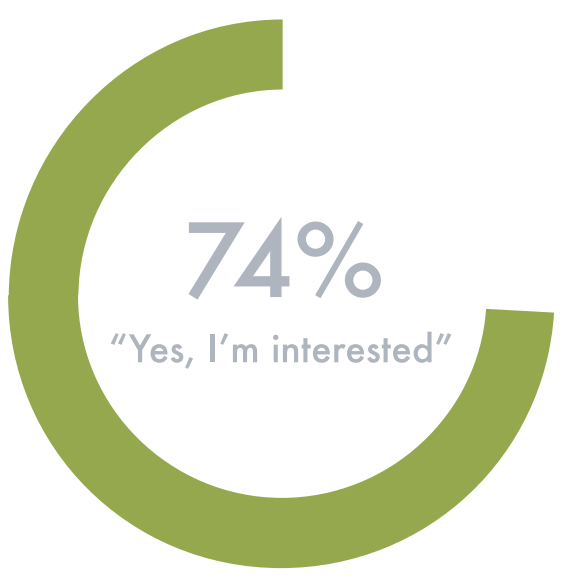

Figure 2: Proportion of boys who were interested / not interested in studying Chemistry after high school.

\section{Summary of Results}

The data collected in this investigation shows a positive correlation between gender and an interest in studying Chemistry at post-secondary levels. Out of the 120 males surveyed, 89 of them intended to study Chemistry at a post-secondary level (74\%); however, out of the 120 females surveyed, only 42 of them did (35\%). More than double the amount of males compare to females plan to study Chemistry. When asked about the quality of teaching, the data fitted the Gaussian distribution (Figure 3). Approximately 65\% of girls reported the quality of chemistry teaching as 7 or higher compared to $40 \%$ of the boys. When asked if they believed that there was a bias and a lack of gender representation in the field of chemistry, $63 \%$ of boys believed there was bias compared to only $27 \%$ of females (Figure 4 ).

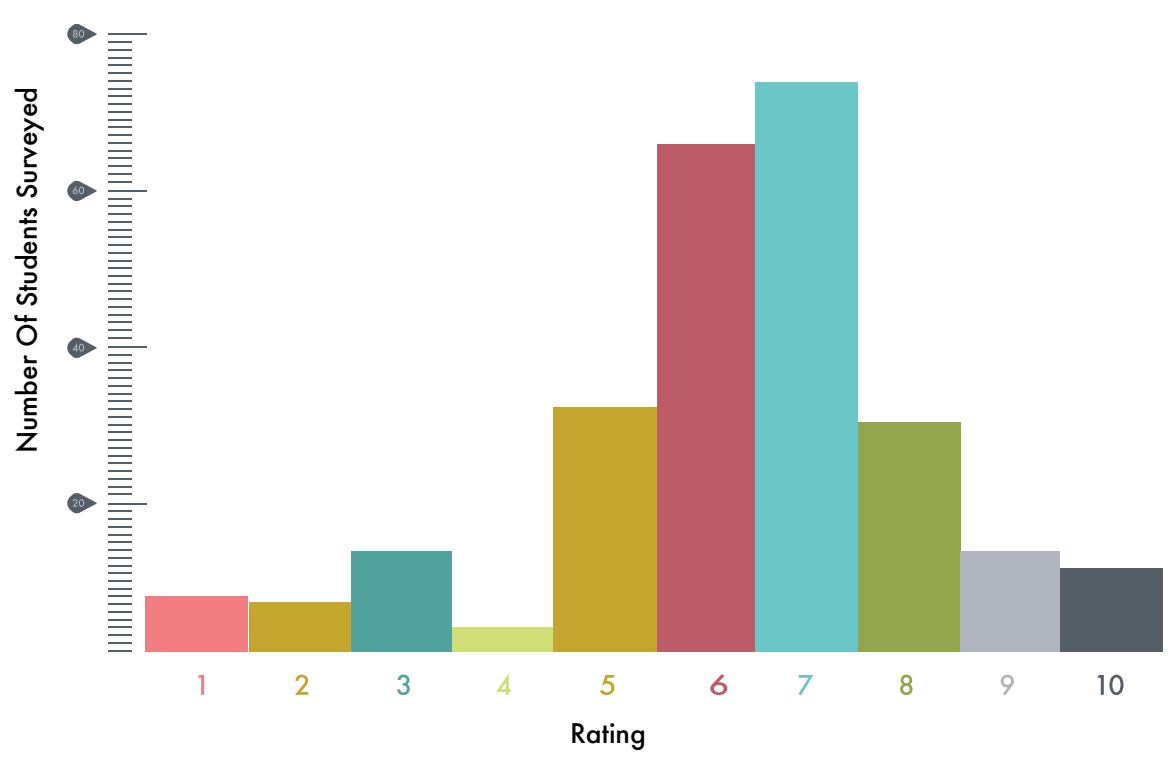

Figure 3: Summary of the ratings for the quality of Chemistry teaching as perceived by both girls and boys in two different high schools in Mississauga. 

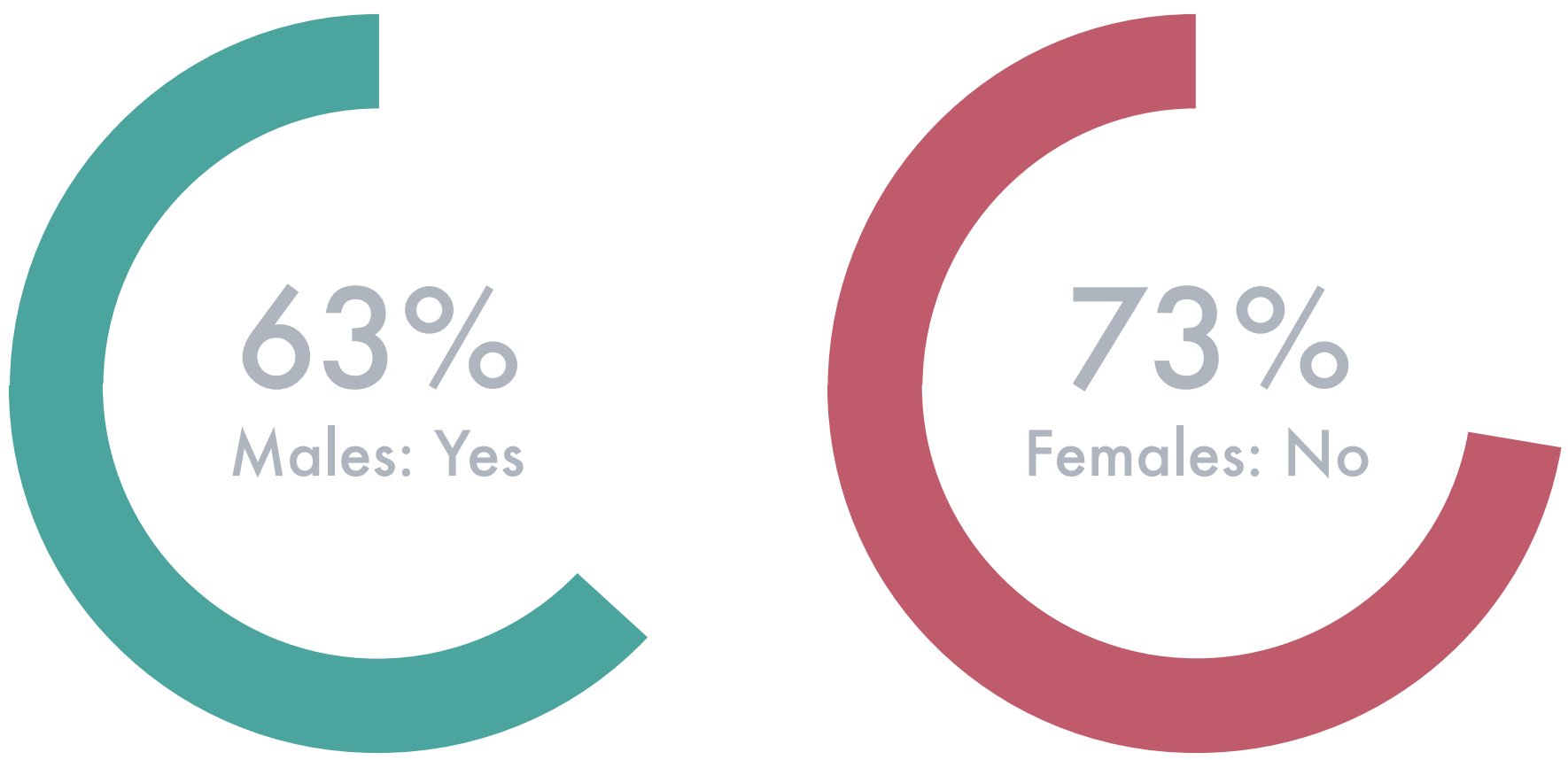

Figure 4: Results on whether males and females thoughts that a gender bias exists

(e.g., underrepresentation of women) in Chemistry.

\section{Discussion \& Implications}

Our research indicates that a gender gap exists in Chemistry, in addition to the other STEM fields. The study suggests that only $35 \%$ of females in two secondary schools in Mississauga have an interest to study Chemistry after high school. This complies with our secondary research, which shows that there is an underrepresentation of women in STEMS fields. However, we recognize that our data is biased as well.

The subjects these females intend to study are ones that the media has stereotypically labeled "female". What may be most troublesome is that women are becoming comfortable with the idea of pursuing non-STEM related fields and fail to see the gender disproportionality that exists in their classrooms, whereas men have identified and noticed this inequality. Two interesting findings in this study are that more girls reported higher quality of teaching of Chemistry; and secondly, more boys find that there is gender bias and underrepresentation of women. It may be that adolescent girls are more compliant and less critical of the teaching quality than boys. Also, girls may have accepted that Chemistry is a more male-dominant field, and thus, they do not perceive it as problematic. However, we see this as a problem in our society. Girls must see themselves as equal with boys when it comes to STEM fields. Teachers play an important role in empowering girls and allowing them to feel equal to boys.

We think that Chemistry curriculum should be more inclusive. Influential female scientists must be introduced to young girls as role models and the imperative roles that females played throughout the history of science must be highlighted. Chemistry classrooms and school hallways need to display women scientists. Teachers need to highlight contributions of women scientists. Young girls must be shown that the potential to study STEM disciplines exists within every girl.

For the action portion of this project, we created posters with female scientists and a description of their accomplishments. We placed the posters in our school and in other locations such as the middle school, the local community centers and local libraries. We wanted to spread the message to a great number of girls.

The following are a few of the posters that we designed. The scientists below are Marie Curie, Rosalind Franklin, and Gertrude Elion. We suggest that other, more contemporary, women scientist be included. And, there should be women representing different races, ethnicities and cultures. Our society will become equal when women are valued just as much as men and we should stand united as we fight for greater gender equality in our world. 

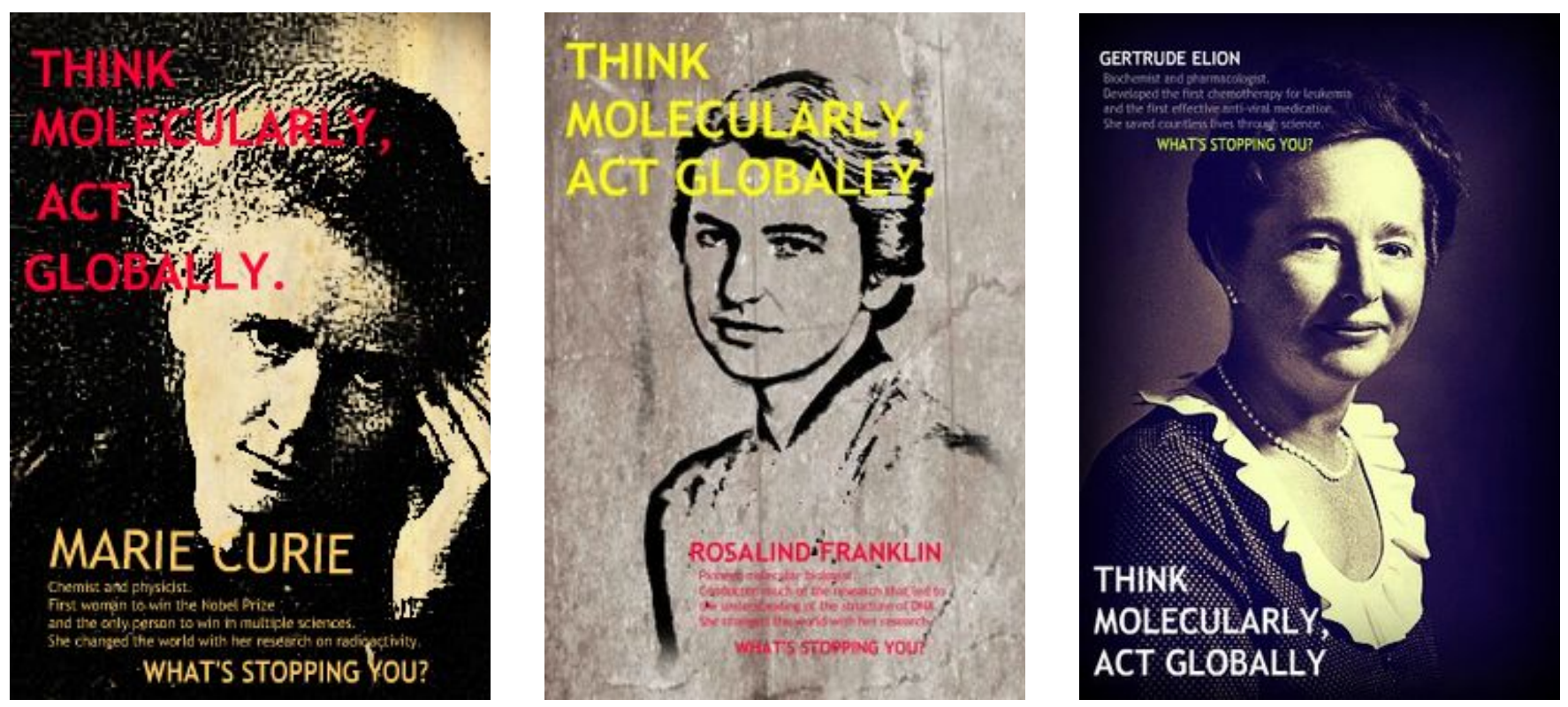

\section{References}

STEM Fields And The Gender Gap: Where Are The Women?. (2012, June 20).

Forbes. Retrieved November 16, 2013, from http://www.forbes.com/sites/work-

in-progress/2012/06/20/stem-fields-and-the-gender-gap-where-are-the-women/

Associated Press. (2007, January 27). PostTV. Washington Post. Retrieved November 16, 2013, from http://www.washingtonpost.com/wp-dyn/content/article/2007/01/27/AR2007012700951.html

The Stem Gender Gap. (n.d.). NPR. Retrieved November 12, 2013, from http:// www.npr.org/2013/08/16/212613885/the-stem-gender-gap

Women in STEM: A Gender Gap to Innovation. (n.d.). US Department of Commerce. Retrieved November 15, 2013, from http://www.esa.doc.gov/sites/default/files/reports/

documents/womeninstemagaptoinnovation8311.pdf 